\title{
Design and Control of a Three-Phase T-Type Inverter using Reverse-Blocking IGBTs
}

\author{
Duong Anh Tuan \\ Hanoi University of Industry \\ Hanoi University of Science and \\ Technology \\ Hanoi, Vietnam \\ duonganhtuan@haui.edu.vn
}

\author{
Phuong $\mathrm{Vu}$ \\ School of Electrical Engineering \\ Hanoi University of Science and \\ Technology \\ Hanoi, Vietnam \\ phuong.vuhoang@hust.edu.vn
}

\author{
Nguyen Van Lien \\ School of Electrical Engineering \\ Hanoi University of Science and \\ Technology \\ Hanoi, Vietnam \\ lien.nguyenvan@hust.edu.vn
}

\begin{abstract}
This paper proposes the design and implementation of a $15 \mathrm{~kW}$ three-phase T-type inverter. Fuji Electric's new generation IGBT module (V series) using RB-IGBT technology is applied for the converter, due to its higher efficiency from conventional IGBTs to reduce switching losses on the semiconductors. Under full load conditions, the overall efficiency of the converter can reach over $98 \%$. The control design and sine PWM modulation are implemented on a DSP kit named TMS320F3F28379D. In addition, the PWM is generated with the fundamental and third harmonics of a sin wave, allowing a modulation factor up to 1,154 compared to traditional PWM. The output voltage of $220 \mathrm{~V} / 50 \mathrm{~Hz}$ with less than $2 \%$ of THD can be achieved at the minimum input DC voltage of $550 \mathrm{~V}$.
\end{abstract}

Keywords-three-phase T-type inverter; Pulse Width Modulation $(P W M)$; digital signal processor

\section{INTRODUCTION}

Nowadays, multilevel inverter structures have been researched widely because of advantages such as their modular structure, simple connection, and maintenance ease. Multi-level inverter structures have various prototypes: Neutral Point Clamped (NPC) [1], Cascaded H-Bridge (CHB) [2], Modular Multilevel Converter (MMC), and T-type inverter [3-4]. Among multilevel inverters, the T-type inverter is considered as an advance prototype of the NP converter. The output voltage of the T-type multilevel inverter reduces harmonics. Furthermore, the dimension of the reactive filter components and the amount of switching devices of the T-type inverter are reduced significantly, which improves the overall efficiency of the system. The T-type inverter is most popular in rooftop solar systems when used for the three-phase grid at the power range of $15 \mathrm{~kW}$ [5].

Conventional IGBTs can oparate at maximum switching frequency of about $20 \mathrm{kHz}$ and the power losses are very high. To deal with this problem, the RB-IGBT technology is used in this research to reduce power losses [6-7]. Fuji's IGBT switches are produced for integrating with T-type structure which makes operation more reliable and efficient [8]. The Pulse Width Modulation (PWM) algorithm combines fundamental and third harmonics, which improve the voltage utilization [9], and allow the converter to operate reliably at a grid with $380 \mathrm{~V} / 50 \mathrm{~Hz}$ voltage. This paper presents the design of the PWM method along with a voltage-current control, which is embedded on a TMS320F3F28379D DSP kit. The experimental system for the three-phase T-type inverter uses the RB-IGBT technology semiconductor. The experiment results verify the effectiveness of the proposed method in improving the system's efficiency.

\section{THE THREE-PHASE T-TYPE INVERTER STRUCTURE USING RB-IGBT}

Figure 1 presents a three-phase three-level T-type inverter structure, which consists of the conventional two-level topology with six switches $\left(S_{A 1}, S_{A 4}, S_{B 1}, S_{B 4}, S_{C l}, S_{C 4}\right)$, while each leg is connected to the neutral point $\mathrm{P}$ of a DC bus through three bidirectional switches $\left(S_{A 2}, S_{A 3}\right),\left(S_{B 2}, S_{B 3}\right),\left(S_{A 2}\right.$, $\left.S_{A 3}\right)$. This circuit diagram can generate 3 levels of phase voltage (as shown in Table I) and 5 levels of line voltage: $+V_{D C},+0.5 V_{D C}, 0,-0.5 V_{D C},-V_{D C}$.

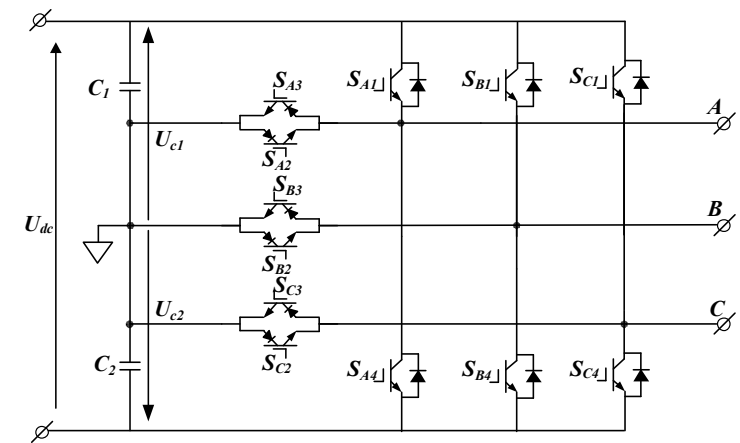

Fig. 1. Three- phase T-type inverter structure.

TABLE I. SWITCH STATUS CORRESPONDING TO VOLTAGE LEVELS AND CAPACITOR STATES

\begin{tabular}{|c|l|l|l|l|c|}
\hline \multirow{2}{*}{ Switching state } & \multicolumn{4}{|c|}{ Valve state (x $\mathbf{A}, \mathbf{B}, \mathbf{C})$} & \multirow{2}{*}{ Output voltage } \\
\cline { 2 - 5 } & $\boldsymbol{S}_{\boldsymbol{~}}$ & $\boldsymbol{S}_{\boldsymbol{~}}$ & $\boldsymbol{S}_{\boldsymbol{x}}$ & $\boldsymbol{S}_{\boldsymbol{x}}$ & \\
\hline$+1 / 2 \mathrm{~V}_{\mathrm{DC}}$ & On & Off & Off & Off & Off \\
\hline 0 & On & Off & Off & Off & On \\
\hline$-1 / 2 \mathrm{~V}_{\mathrm{DC}}$ & Off & On & On & Off & On \\
\hline
\end{tabular}




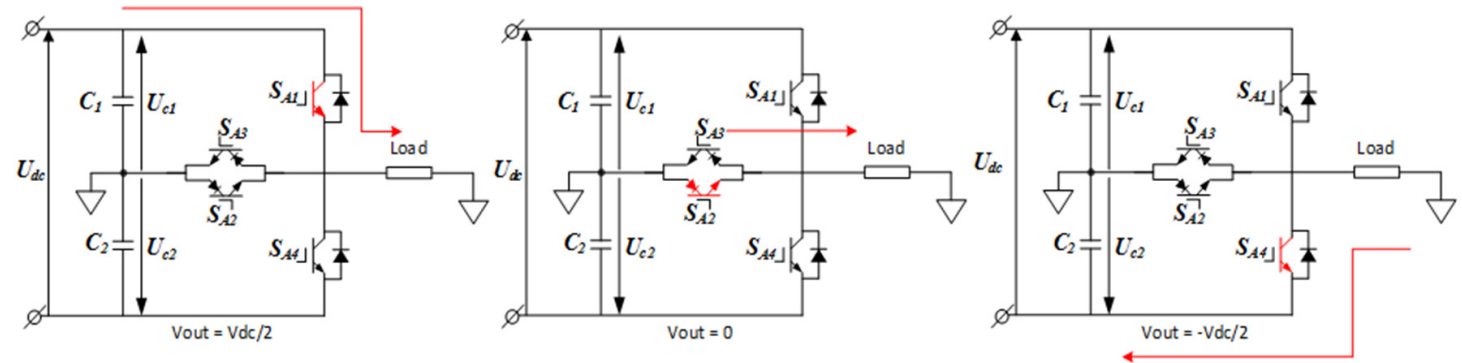

Fig. 2. Phase A current and output voltage status of the three-phase T-type inverter.

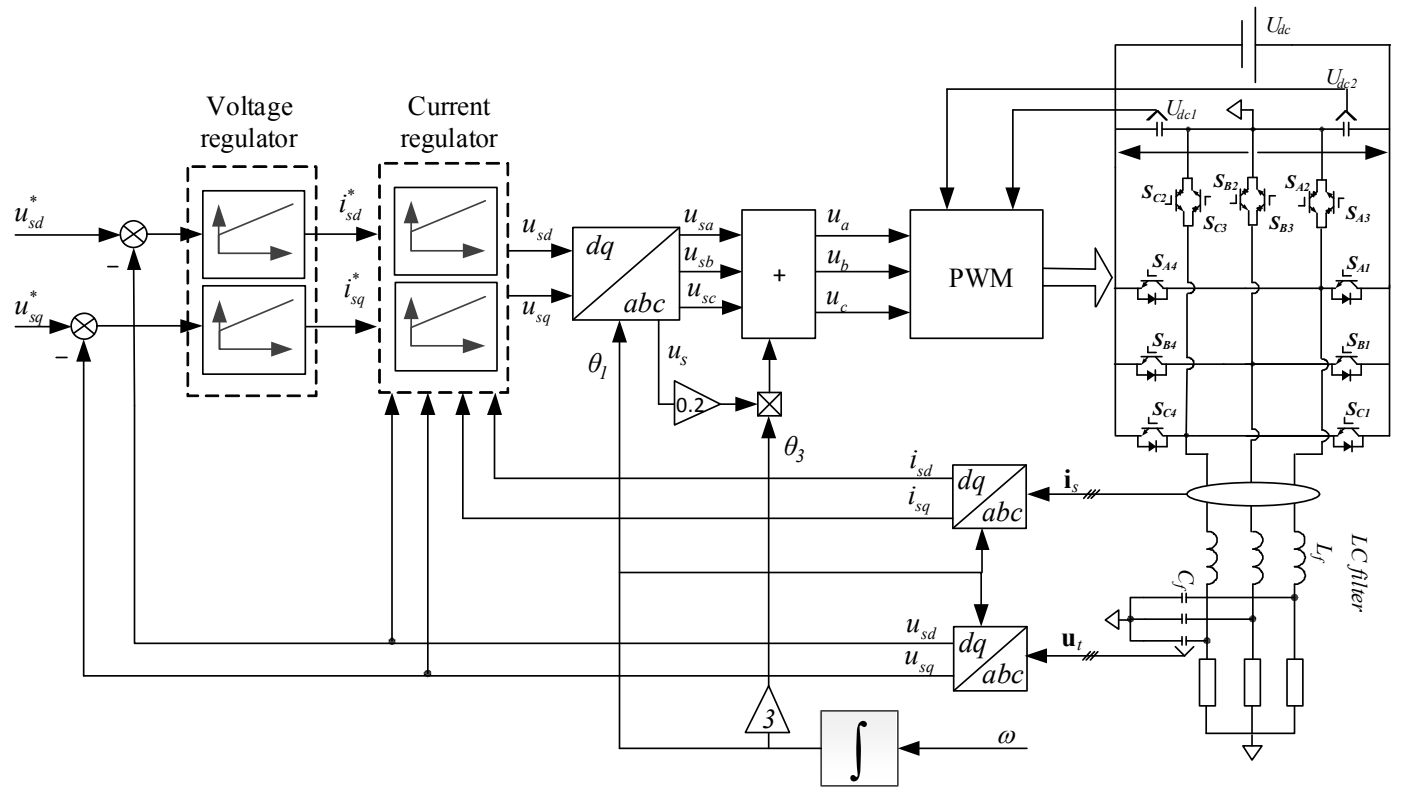

Fig. 3. The control structure of the three-phase T-type inverter applied in standalone mode.

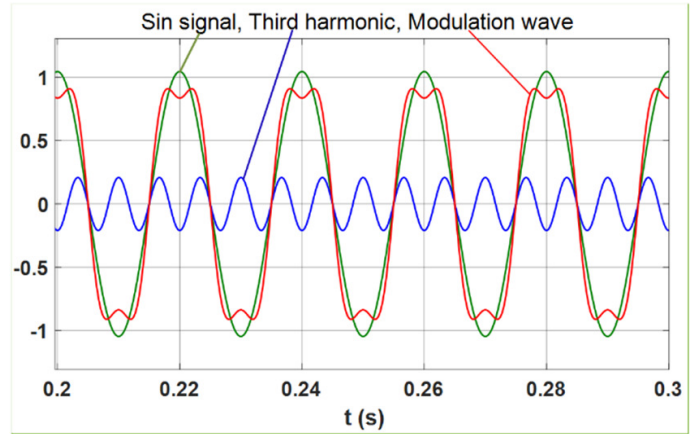

Fig. 4. Modulation method with 3rd harmonic combination.

The operation states of the switching devices in Table I are shown in detail in Figure 2. As can be observed, only one device has switched with corresponding current path in one state. Figure 3 shows the control strategy of the three-phase Ttype inverter in standalone mode. In this research, the modulation waves of each phase include single-phase standard sine wave combined with a third harmonic [10-13], as presented in Figure 4. The final modulation waves for the three phases are compared to the shift-level carrier pulse in Figure 5. Besides, by reversing the status of $S_{A 1}, S_{A 2}, S_{B 1}, S_{B 2}, S_{C 1}, S_{C 2}$, the

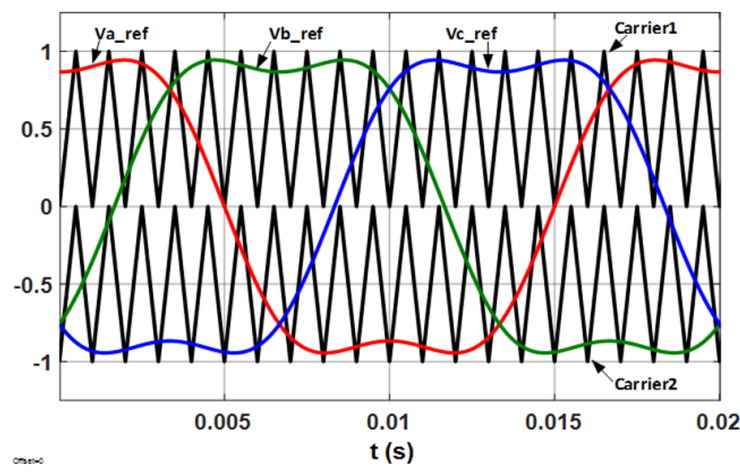

Fig. 5. The three-phase modulation index.

operate states of switches $S_{A 3}, S_{A 4}, S_{B 3}, S_{B 4}, S_{C 3}, S_{C 4}$ can be obtained, respectively. In the three-phase system, the voltage vector $u_{s}$ is represented by $u_{a}, u_{b}, u_{c}$ with $120^{\circ}$ phase angles between them:

$$
\begin{gathered}
u_{a}=m_{a} \cos (\omega t) \\
u_{b}=m_{a} \cos \left(\omega t-\frac{2}{3} \pi\right)
\end{gathered}
$$




$$
u_{c}=m_{a} \cos \left(\omega t+\frac{2}{3} \pi\right)
$$

where $m_{a}$ is duty cycle of the PWM modulation method (Figure 4). According to [14], the third harmonic injected $u_{0}$ (THI) is added to the fundamental sine wave with amplitude equal to 0.2 times that of the voltage amplitude $u_{s}$ :

$$
\begin{aligned}
& V_{a_{-} \text {ref }}=u_{a}+u_{0} \\
& V_{b_{-} \text {ref }}=u_{a}+u_{0} \\
& V_{c_{\text {_ref }}}=u_{a}+u_{0}
\end{aligned}
$$

where:

$$
u_{o}=0.2 m_{a_{-} \max } \cos (3 \omega t)=0.2 \cos (3 \omega t)
$$

Equations (8)-(9) illustrate the linear relationship between the output current and the control signal is the corresponding voltage:

$$
\begin{aligned}
& \left\{\begin{array}{l}
v_{s d}^{*}=r_{L} i_{s d}+L_{f} \frac{d i_{s d}}{d t}-\omega_{s} L_{f} i_{s q}+v_{L d} \\
v_{s q}^{*}=r_{L} i_{s q}+L_{f} \frac{d i_{s q}}{d t}-\omega_{s} L_{f} i_{s d}+v_{L q}
\end{array}\right. \\
& \left\{\begin{array}{l}
v_{s d}^{*}=\Delta v_{d}+v_{L d}-\omega_{s} L_{f} i_{s q} \\
v_{s q}{ }^{*}=\Delta v_{q}+v_{L q}-\omega_{s} L_{f}{ }_{s d}
\end{array}\right.
\end{aligned}
$$

The cross-channeled components and the noise of load voltage are removed by cross-compensation and the integral part of the current controller, as shown in Figures 6-7.

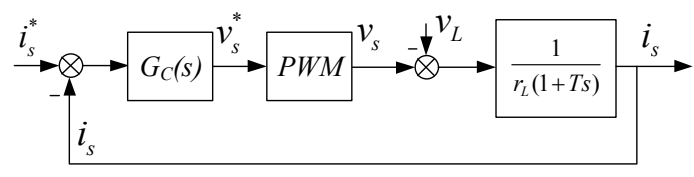

Fig. 6. The current loop structure.

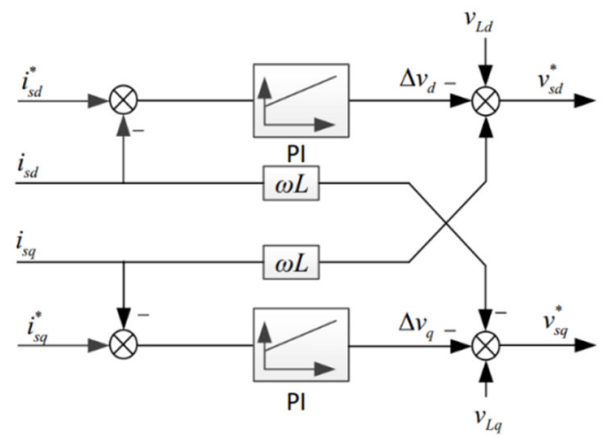

Fig. 7. The decoupling current control for the three-phase T-type inverter.

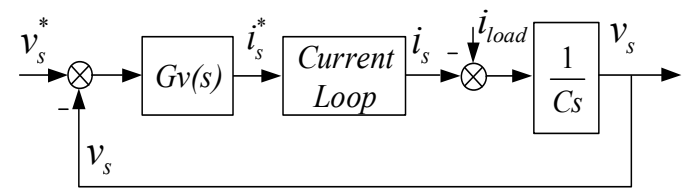

Fig. 8. The voltage loop structure

The mathematical model of the voltage controller is similar to the current controller's in dq coordinates. The three- phase currents based on Kirchhoff equation are transformed into rotary $\mathrm{d}-\mathrm{q}$ coordinates with fundamental rotating speed of output voltage $\omega$ :

$$
\left\{\begin{array}{l}
i_{s d}=i_{L d}+C_{f} \frac{d v_{L d}}{d t}-\omega_{s} L_{f}{ }^{v} L q \\
i_{s q}=i_{L q}+C_{f} \frac{d v_{L q}}{d t}-\omega_{S} C_{f} i_{s d}{ }^{v} L d
\end{array}\right.
$$

Assuming that the close-loop of the transfer current is approximately 1 , the relationship between load and reference voltage is rewritten from (9):

$$
\left\{\begin{array}{l}
\frac{v_{L d}(s)}{i_{s d}^{*}(s)} \approx \frac{1}{C s} \\
\frac{v_{L q}(s)}{i_{s q}^{*}(s)} \approx \frac{1}{C s}
\end{array}\right.
$$

By applying Clarke and Park transforms, the control method in this paper implements the PI controller for current components in d-q coordinates. The current controller uses the cross-channeled control which is based on the control method of three-phase AC machines [15]. The outputs of the current controller are converted to abc coordinates by Park transform, then they are added to THI to obtain the duty cycle. Finally, the duty cycle will be applied in the PWM modulator to generate the pulses for the switching devices.

\section{PROTOTYPE IMPLEMENTATION}

The DSP TMS320F28379D is a static 32bit microcontroller of Texas Instruments. The microcontroller series allows operation with quartz frequencies up to $200 \mathrm{MHz}$. In addition, it integrates the 32-bit floating-point arithmetic engine called CLA (Control Law Accelerator) for computational processing. The control algorithm is run in parallel with the other tasks on the CPU. The control structure for the T-type multi-level converter is implemented on the DSP. The time frame of the program on DSP for the converter is shown on Figure 9. PWM1 is initialized in "up-down" mode, generating pulses at $10 \mathrm{kHz}$, and after 2 periods, the ADC is triggered when the counter of PWM equals to TBPRB. The ADC A0, A1, A2, B2, $\mathrm{C} 2, \mathrm{~A} 3, \mathrm{~B} 3, \mathrm{C} 3$ start converting the analog signals $\left(u_{d c}, u_{d c 2}\right.$, $\left.u_{s a}, u_{s b}, u_{s c}, i_{s a}, i_{s b}, i_{s c}\right)$. When the ADC conversion is done, the program in CLA interrupt is triggered (task1). The current controller is executed with the 200us-sampling-period $T i$, which is twice the pulse period Tpulse. The output voltage controller is executed with the $2 \mathrm{~ms}$-sampling-period, which is 
ten times the sampling period of the current controller. After finishing the calculation in CLA, the new duty cycle values are updated to PWM registers. Before updating the value to the PWM channels for the next time, the calculation of the modualtion index must be conducted. The PWM value is updated at the instant when the counter of the PWM channel equals to 0 . So, the execution time of the program must be less than the half of the period cycle, which is about $50 \mu \mathrm{s}$. As can be observed, the total program execution time of only $4.89 \mu \mathrm{s}$ is smaller than this time limitation. The experimental system uses a three-phase bridge rectifier and capacitor system to generate DC voltage. To increase the DC voltage, a $24.7 \mathrm{~kW}$ transformer is applied in front of the rectifier bridge along with a capacitor system to reduce DC voltage fluctuations on the DC bus. The three-phase T-type inverter system is controlled in a standalone mode. A Yokogawa M\&C Corporation CW140 [16] Clamp-on Power Meter is connected to measure the input and output of the converter to evaluate the efficiency as shown on Figure 10.

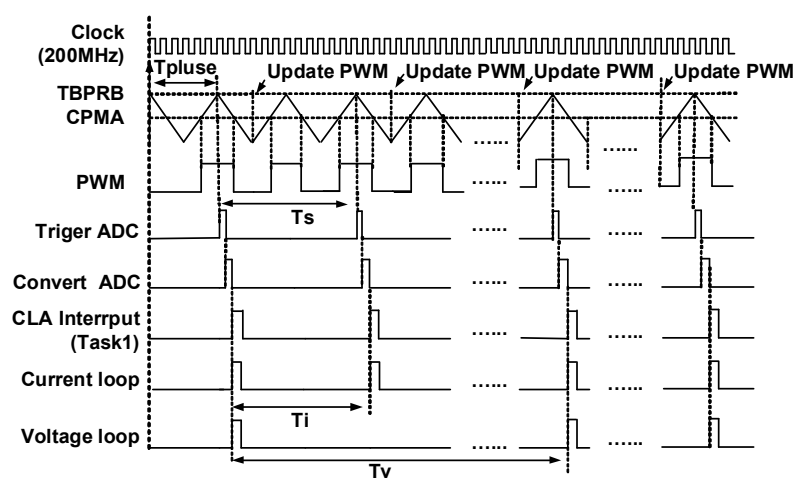

Fig. 9. Time frame of implementation on the DSP.

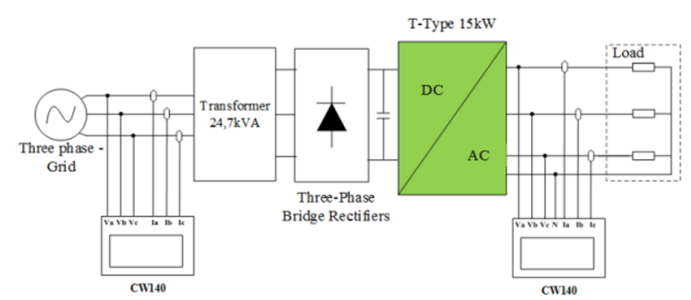

Fig. 10. The experimental model of the three-phase T-type inverter.

\section{EXPERIMENTAL RESULTS}

The experiment parameters of the control system are shown in Table II. The modulation of the third harmonic is shown on Figure 12. Figure 13 illustrates $u_{s d}$ and $u_{s q}$ voltage responses. Figure 14 shows $i_{s d}$ and $i_{s q}$ current responses on $\mathrm{d}-\mathrm{q}$ coordinates, which are moved out to DAC of the control card. Similarly, voltages $u_{s d}$ and $u_{s q}$ are set to be $220 \sqrt{2}$ and 0 respectively, so that the power factor equals to 1 . The output of the voltage controller is the set value for the current controller. The set value of the voltage controller ramps in $0.5 \mathrm{~s}$ time. This ramp could reduce and prevent the system from over-current and over-voltage while starting. Besides, the responses of the controllers are not affected while changing loads.
TABLE II. REAL CIRCUIT PARAMETERS

\begin{tabular}{|c|c|c|}
\hline Sign & Parameters & Value \\
\hline$V_{D C}$ & Input DC voltage & $600 \mathrm{VDC}$ \\
\hline$V_{r m s}$ & Output phase voltage & $220 \mathrm{VAC}$ \\
\hline$f_{l}$ & Basic frequency & $50 \mathrm{~Hz}$ \\
\hline$f_{s}$ & Pulse frequency & $10 \mathrm{kHz}$ \\
\hline$L_{f}$ & Filter inductors & $0.8 \mathrm{mH}$ \\
\hline$r_{f}$ & Inductors resistor & $0.1 \Omega$ \\
\hline$C_{f}$ & Filter capacitors & $20 \mu \mathrm{F}$ \\
\hline$C_{l}, C_{2}$ & DC capacitors & $940 \mu \mathrm{F}$ \\
\hline IGBT Fuji & $12 \mathrm{MBI} 100 \mathrm{VN}-120-50(1,2 \mathrm{kV} / 100 \mathrm{~A})$ \\
\hline $\begin{array}{c}\text { Controller } \\
\text { Card }\end{array}$ & \multicolumn{2}{|c}{ TMS320F28379D } \\
\hline
\end{tabular}

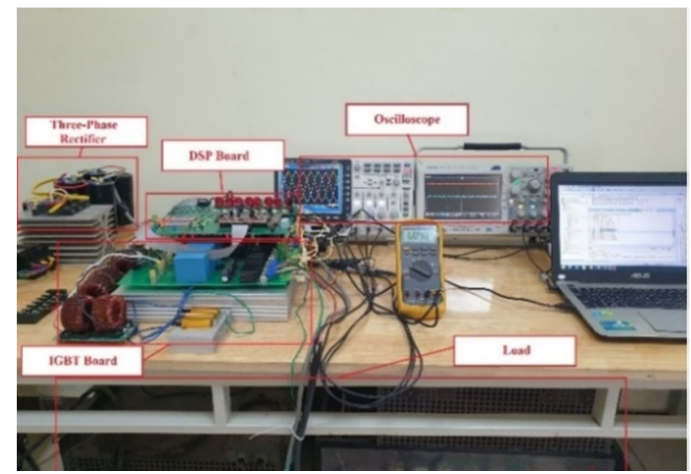

Fig. 11. The experimental model of the three-phase T-type inverter.

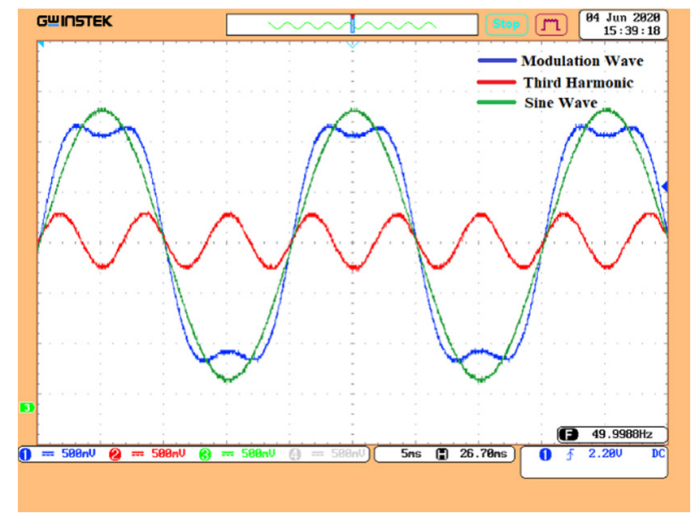

Fig. 12. Modulation method with 3rd harmonic combination.

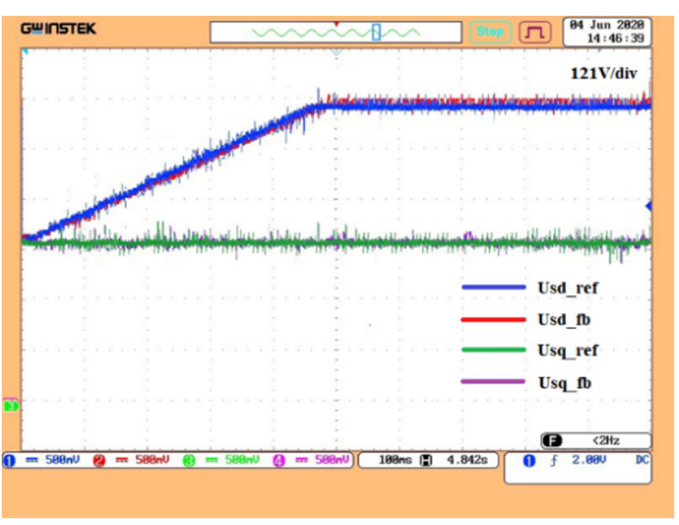

Fig. 13. $\quad u_{s d}$ and $u_{s q}$ voltage responses. 


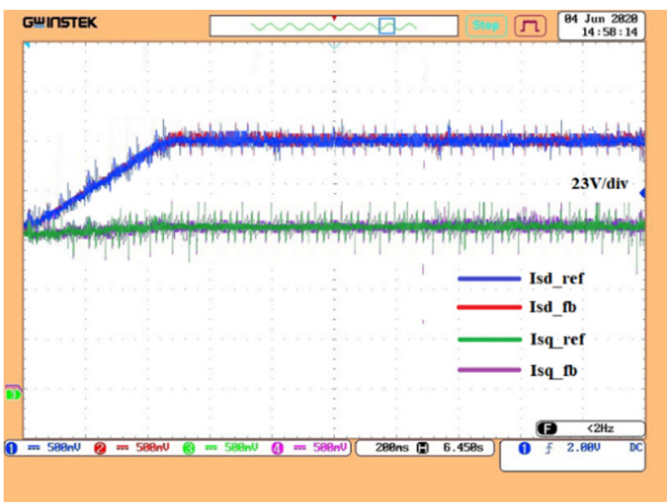

Fig. 14. $\quad \mathrm{I}_{\mathrm{sd}}$ and $\mathrm{I}_{\mathrm{sq}}$ current responses.

The voltage of the DC bus is $560 \mathrm{~V}$ as shown in Figure 15, and the voltages on $C_{1}$ and $C_{2}$ capacitors fluctuate around $280 \mathrm{~V}$. Figure 16 illustrates the fluctuation of voltages on $C_{l}$ and $C_{2}$, with the magnitude $\Delta V_{C}=10 \mathrm{~V}$. The voltage of the DC bus is fluctuating due to the diode bridge rectifier. Three-phase load current, output line voltage Vab before filter, and LC filter output three-phase voltage are shown in Figures 18, 19, and 20 respectively. The output voltage of the three-phase T-type inverter has an rms value of $220 \mathrm{~V}$ and the THD is $2.7 \%$, at $15 \mathrm{~kW}$. The efficiency reaches its highest value of over $98 \%$, as presented in Figure 17 under full-load condition. Since the input DC power is powered by a 3-phase diode rectifier, the DC voltage ripples 6 times to grid voltage frequency.

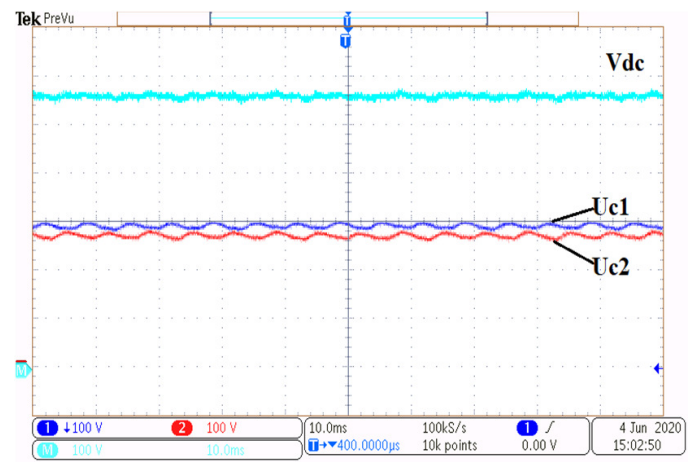

Fig. 15. The voltages on $\mathrm{C}_{1}$ and $\mathrm{C}_{2}$ capacitors and the $\mathrm{DC}$ bus voltage.

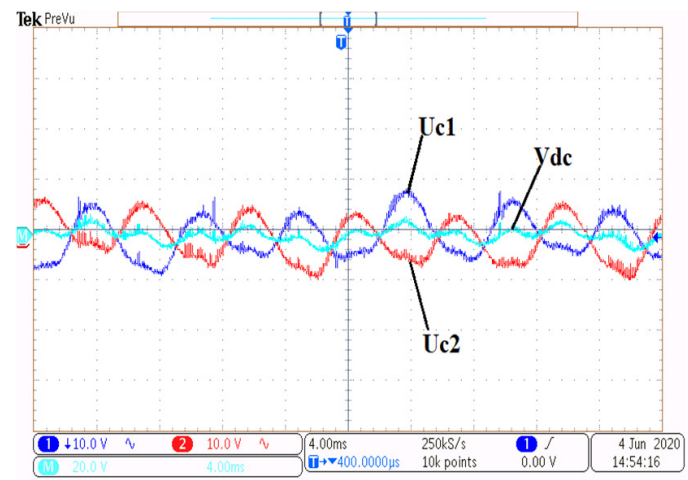

Fig. 16. The difference of voltages between capacitors.

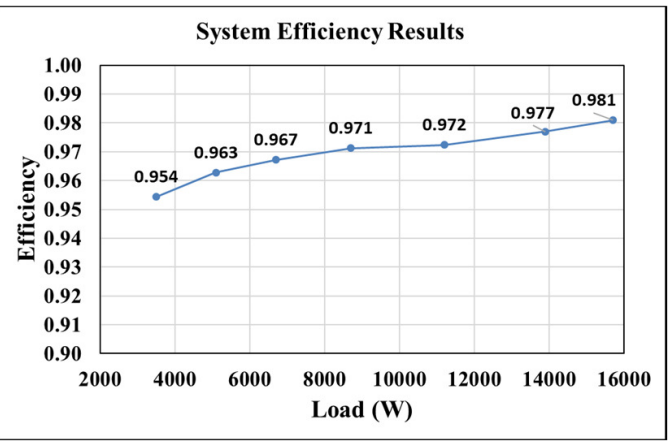

Fig. 17. The converter's efficiency.

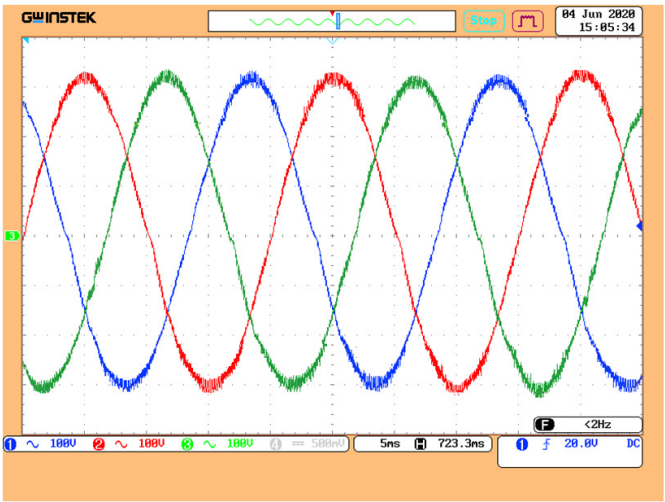

Fig. 18. The three-phase load currents.

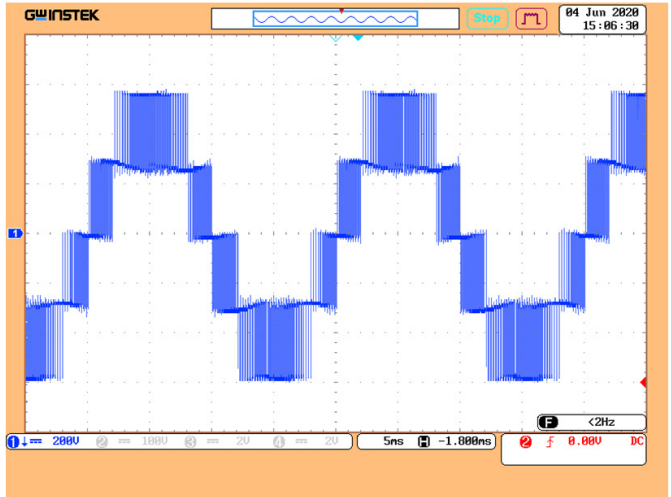

Fig. 19. Output line voltage before filter.

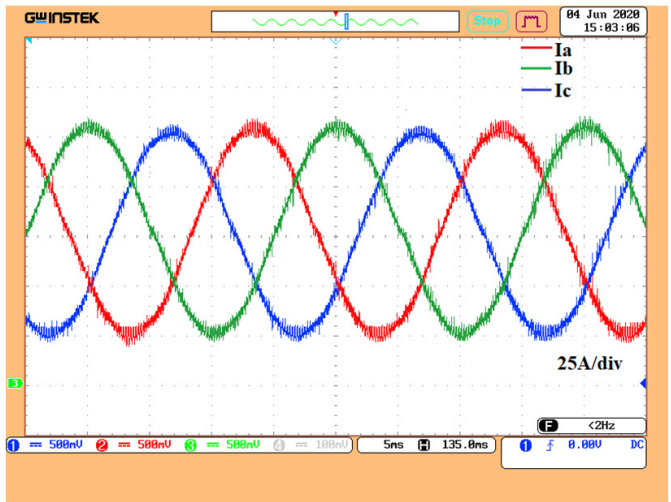

Fig. 20. The LC filter output phase voltages. 


\section{CONCLUSION}

In the current paper, a three-phase T-type inverter at the power range of $15 \mathrm{~kW}$ was designed and implemented. The controller card TMS320F28379D which is capable of calculating floating-point and processing signals quickly was ultilized in this research. The PWM-THI modulation method is applied due to its higher than conventional PWM modulation factor. After combining the modulation and control methods, the stand-alone three-phase T-type inverter with input voltage of $600 \mathrm{~V}$ is controlled stably to generate an output voltage of $220 \mathrm{~V}$, with power rating of $15 \mathrm{~kW}$ with $2.7 \%$ current THD and $98 \%$ full-load condition efficiency.

\section{REFERENCES}

[1] M. Rezki and I. Griche, "Simulation and Modeling of a Five -Level (NPC) Inverter Fed by a Photovoltaic Generator and Integrated in a Hybrid Wind-PV Power System," Engineering, Technology \& Applied Science Research, vol. 7, no. 4, pp. 1759-1764, Aug. 2017, https://doi.org/10.48084/etasr.1271.

[2] Y. Gopal, K. P. Panda, D. Birla, and M. Lalwani, "Swarm OptimizationBased Modified Selective Harmonic Elimination PWM Technique Application in Symmetrical H-Bridge Type Multilevel Inverters," Engineering, Technology \& Applied Science Research, vol. 9, no. 1, pp. 3836-3845, Feb. 2019, https://doi.org/10.48084/etasr.2397.

[3] R. A. Rana, S. A. Patel, A. Muthusamy, C. woo Lee, and H.-J. Kim, "Review of Multilevel Voltage Source Inverter Topologies and Analysis of Harmonics Distortions in FC-MLI," Electronics, vol. 8, no. 11, Nov. 2019, Art. no. 1329, https://doi.org/10.3390/electronics8111329.

[4] C. L. Solanki, M. H. Ayalani, and S. N. Gohil, "Performance of Three Phase T-Type Multilevel Inverter with Reduced Switch Count," in 2018 International Conference on Current Trends towards Converging Technologies (ICCTCT), Mar. 2018, pp. 1-5, https://doi.org/ 10.1109/ICCTCT.2018.8550937.

[5] A. Salem and M. A. Abido, "T-Type Multilevel Converter Topologies: A Comprehensive Review," Arabian Journal for Science and Engineering, vol. 44, no. 3, pp. 1713-1735, Mar. 2019, https://doi.org/ 10.1007/s13369-018-3506-6.

[6] C. Klumpner and F. Blaabjerg, "Using reverse-blocking IGBTs in power converters for adjustable-speed drives," IEEE Transactions on Industry Applications, vol. 42, no. 3, pp. 807-816, May 2006, https://doi.org/ 10.1109/TIA.2006.872956

[7] T. Naito, M. Takei, M. Nemoto, T. Hayashi, and K. Ueno, "1200V reverse blocking IGBT with low loss for matrix converter," in 2004 Proceedings of the 16th International Symposium on Power Semiconductor Devices and ICs, Kitakyushu, Japan, May 2004, pp. 125128, https://doi.org/10.1109/WCT.2004.239842.

[8] P. J. Grbovic, F. Gruson, N. Idir, and P. L. Moigne, "Turn-on Performance of Reverse Blocking IGBT (RB IGBT) and Optimization Using Advanced Gate Driver," IEEE Transactions on Power Electronics, vol. 25, no. 4, pp. 970-980, Apr. 2010, https://doi.org/ 10.1109/TPEL.2009.2031805.

[9] M. Sajitha, J. Sandeep, and R. Ramchand, "Comparative Analysis of Different Modulation Techniques for Three Level Three Phase T-type NPC Inverter," in TENCON 2019 - 2019 IEEE Region 10 Conference (TENCON), Kochi, India, Oct. 2019, pp. 1529-1534, https://doi.org/ 10.1109/TENCON.2019.8929574.

[10] J. Huang, Q. Liu, X. Wang, and K. Li, "A Carrier-Based Modulation Scheme to Reduce the Third Harmonic Component of Common-Mode Voltage in a Three-Phase Inverter Under High DC Voltage Utilization," IEEE Transactions on Industrial Electronics, vol. 65, no. 3, pp. 19311940, Mar. 2018, https://doi.org/10.1109/TIE.2017.2745439.

[11] A. Yang, L. Pamungkas, Y. Chang, J. Lin, and H. Chiu, "Design and Implementation of $6 \mathrm{~kW}$ Three-Phase T-Type Inverter for Microgrid Application," in 2018 International Conference on Applied Engineering (ICAE), Batam, Indonesia, Oct. 2018, pp. 1-5, https://doi.org/ 10.1109/INCAE.2018.8579417.
[12] J. Jose, G. N. Goyal, and M. V. Aware, "Improved inverter utilisation using third harmonic injection," in 2010 Joint International Conference on Power Electronics, Drives and Energy Systems 2010 Power India, Dec. 2010, pp. 1-6, https://doi.org/10.1109/PEDES.2010.5712490.

[13] L. Chaturvedi, D. K. Yadav, and G. Pancholi, "Comparison of SPWM,THIPWM and PDPWM Technique Based Voltage Source Inverters for Application in Renewable Energy," Journal of Green Engineering, vol. 7, no. 1, pp. 83-98, Jan. 2017, https://doi.org/ 10.13052/jge1904-4720.7125.

[14] W. Subsingha, "A Comparative Study of Sinusoidal PWM and Third Harmonic Injected PWM Reference Signal on Five Level Diode Clamp Inverter," Energy Procedia, vol. 89, pp. 137-148, Jun. 2016, https://doi.org/10.1016/j. egypro.2016.05.020.

[15] N. Dong, H. Yang, J. Han, and R. Zhao, "Modeling and Parameter Design of Voltage-Controlled Inverters Based on Discrete Control," Energies, vol. 11, no. 8, Aug. 2018, Art. no. 2154, https://doi.org/ 10.3390/en1 1082154.

[16] M. Kawasaki, K. Funaki, and A. Morita, "CW140 Clamp-on Power Meter," Yokogawa Technical Report Enghlish Edition 31, 2001. 